\title{
HISTÓRIA DA DISCIPLINA “LITERATURA INFANTIL" NOS CURSOS DE FORMAÇÃO DE PROFESSORES NO ESTADO DE SÃO PAULO (1947-2003)
}

\author{
Fernando Rodrigues de Oliveira
}

UNESP

\section{RESUMO}

Com os objetivos de contribuir para a compreensão da história do ensino da literatura infantil nos cursos de formação de professores brasileiros e contribuir para a compreensão de aspectos ainda pouco explorados da história das disciplinas escolares, focaliza, neste artigo, aspectos do modo como foi prescrito e organizado o ensino da literatura infantil nos cursos de formação de professores primários no estado de São Paulo, no período compreendido entre 1947 e 2003, datas, respectivamente, da primeira e da última vez em que se constata a presença da matéria/disciplina "Literatura infantil" nos currículos desses cursos. Para tanto, mediante abordagem histórica, centrada em pesquisa documental e bibliográfica, reuniu-se diferentes documentos sobre a formação de professores e sobre o "ensinar a ensinar" literatura infantil no estado de São Paulo. A análise desses documentos possibilitou compreender aspectos importantes da história da disciplina "literatura infantil" no âmbito da história da formação de professores, como a sua contribuição para a conformação de práticas desse ensino ainda em vigência no Brasil.

Palavras-chave: Disciplinas Escolares; Literatura infantil; Formação de professores; História da Educação.

\section{HISTORY OF SCHOOL SUBJECT "CHILDREN LITERATURE" IN TEACHER EDUCATION COURSES IN SÃO PAULO STATE (1947-2003)}

\begin{abstract}
Aiming to contribute to the understanding of the history teaching children's literature in the teacher Education courses in Brazil and contribute to the understanding of unexplored aspects of the history of school subjects, it is focused in this article, aspects of how it was prescribed and organized the teaching of children's literature in teacher education courses for primary school in the state of São Paulo, between 1947 and 2003, dates, respectively, the first and last time we see the presence of the school subject "Children's Literature" in the curricula of these courses. For that, by historical approach, focusing on documentary and bibliographic research, it was recovered different documents about teacher education and about "teach to teach" children's literature in the state of São Paulo. The analysis of these documents enabled us to understand important aspects of the history of the school subject "children's literature" in the teacher education courses, as its contribution to the formation of such teaching practices still in force in Brazil.

Keywords: School Subjects; Children's literature; Teacher education; History of Education.
\end{abstract}




\section{Introdução}

No âmbito dos estudos brasileiros sobre História da Educação, considerando o conjunto de temas que ainda carecem de maior atenção por parte dos pesquisadores envolvidos com esse campo de conhecimento, as questões relativas ao ensino da literatura infantil podem parecer pouco relacionadas com o nosso passado educacional. No entanto, embora o estudo das questões ligadas a esse gênero literário venha sendo mais recorrentemente debatido em outras áreas, que não a História da Educação ${ }^{1}$, a literatura infantil, mais do que qualquer outro gênero literário, originou-se e vem se desenvolvendo sob a tutela da escola, relacionando-se diretamente com a formação de crianças e jovens no Brasil.

Essa relação entre educação e literatura infantil decorre, sobretudo, do fato de esse gênero literário ter-se formado, no final do século XIX, a partir dos livros de leitura, os quais eram destinados ao uso nas escolas primárias para se ensinar a ler. Na medida em que esses livros passaram a apresentar, além das características estritamente didáticas, relações com a "cultura do maravilhoso" e com o "fantástico", foi-se delineando um corpus de livros que passamos a denominar de "Literatura infantil" (ARROYO, 1968).

Ainda no final do século XIX e início do século XX, conforme esses livros de leitura foram sendo publicados, "[...] não era possível estabelecer uma separação nítida entre os de entretenimento puro e os de leitura para aquisição de conhecimentos e estudos nas escolas [...]" (ARROYO, 1968, p. 93). Essa distinção foi sendo possível de ser feita somente ao longo do século $\mathrm{XX}$, o que não significo, também, o distanciamento da literatura infantil com as questões educacionais. Ainda que os "livros de entretenimento" não tivessem pretensões didáticas, o seu uso ainda estava (e está) ligado à formação escolarizada de crianças e jovens.

Por essa razão, pensar o "lugar" da literatura infantil na História da Educação tem sua relevância, uma vez que o debate sobre a produção, circulação e ensino desse gênero literário esteve interligado fortemente com a Educação brasileira.

Tal foi/é a relação entre esses campos, que, no final da primeira metade do século $\mathrm{XX}$, educadores e intelectuais da época passaram a debater sobre o assunto, o que ocasionou, em 1947, a criação da matéria "Literatura infantil" nos Cursos Normais do estado de São Paulo. Tornando-se, com isso, obrigatório, nesse estado, o ensino da literatura infantil na formação de professores.

Esse ensino permaneceu com algumas mudanças nos programas e currículos dos cursos de formação de professores do estado de São Paulo até o ano de 2003, quando foram extintos os cursos de formação em nível médio (os chamados cursos de Magistério).

Em vista do exposto, com os objetivos de contribuir para a compreensão da história do ensino da literatura infantil nos cursos de formação de professores e contribuir para a compreensão de aspectos ainda pouco explorados da história das disciplinas escolares e da história da educação brasileira, apresento, neste $\operatorname{artigo}^{2}$, aspectos do modo como foi organizado e prescrito o ensino da literatura infantil nos Cursos Normais, de Escolas Normais e Institutos de Educação, nas Habilitações Específicas de $2^{\circ}$ grau para o Magistério (HEM) e nos Centros Específicos de Formação e Aperfeiçoamento do Magistério (CEFAM), todos cursos que formaram professores no estado de São Paulo no período compreendido entre 1947 e 2003. Essas datas referem-se, respectivamente, à primeira e à última vez em que se constata a presença da matéria/disciplina "Literatura infantil" nos currículos desses cursos. 
Para tanto, apresento aspectos dos documentos oficiais, como leis, decretos, resoluções e programas de ensino, relativos à institucionalização da matéria/disciplina "Literatura infantil" nos cursos de formação de professores no estado de São Paulo. A opção por analisar os documentos oficiais para pensar a história da disciplina "Literatura infantil" decorreu do fato de que são nesses documentos que estão contidas as normatizações em relação a criação e operacionalização dessa disciplina.

\section{A Lei Orgânica do Ensino Normal, a reforma dos Cursos Normais e a criação da matéria "Literatura infantil", em 1947}

No caso brasileiro, após a instauração do regime político que ficou conhecido como Estado Novo, a partir de 1937, no conjunto das mudanças realizadas pelo governo para atender às urgências e necessidades da época, iniciou-se, no âmbito educacional, um período de reformas educacionais a partir das chamadas "leis orgânicas do ensino". Essas leis foram promulgadas entre 1942 e 1946 e foram elaboradas por uma comissão presidida pelo então Ministro da Educação e Saúde, Gustavo Capanema.

No caso dos cursos de formação de professores primários, a Lei Orgânica do Ensino Normal, Decreto-lei n. 8.530, de 2 de janeiro de 1946, foi publicada com a finalidade de estabelecer algumas mudanças nesses cursos, dentre as quais: um Curso Normal dividido em dois ciclos, o de regente do ensino primário, em quatro anos, e o de formação de professores primários, em três anos; e a criação dos cursos de especialização para administradores escolares (TANURI, 2000).

Os Cursos Normais do estado de São Paulo, para se adequarem à Lei Orgânica do Ensino Normal, foram reformulados a partir do Decreto n. 17.698, de 26 de novembro de 1947. Dentre as mudanças ocorridas em decorrência desse Decreto de 1947, os Cursos Normais desse estado passaram a ser organizados em Pré-Normal, com duração de um ano, e um curso de Formação Profissional do Professor, com duração de dois anos.

Por conta disso, esse Decreto de 1947 também foi responsável pelo estabelecimento de uma nova organização do currículo dos Cursos Normais no estado de São Paulo e, com isso, o Curso de Formação Profissional do Professor ficou organizado em quatro seções: $1^{\text {a }}$. seção "Educação"; 2a . seção "Biologia Educacional", 3". seção "Sociologia"; e 4". seção “Artes”. (SÃO PAULO, 1947).

De acordo com o currículo estabelecido pelo Decreto de 1947, a matéria "Literatura infantil" não constava no currículo dos Cursos Normais ministrados nas Escolas Normais paulistas. Essa matéria constava apenas no currículo do Curso Normal oferecido no Instituto de Educação (IE) "Caetano de Campos", localizado na capital paulista, que tinha uma organização diferenciada da dos demais Cursos Normais do estado, conforme esse Decreto de 1947.

Em relação à diferença de organização do Curso Normal do IE "Caetano de Campos", de acordo com o Decreto $\mathrm{n}^{\circ} .17 .698$, de 26 de novembro de 1947, esse curso ficou organizado em três anos, destinando-se a formar os professores pré-primários, ou seja, os professores do jardim de infância, e os professores primários.

Também conforme esse Decreto de 1947, o currículo do Curso Normal do IE "Caetano de Campos" compreendia as seguintes matérias: Português; História da Civilização Brasileira; Matemática; Física e Química; Anatomia e Fisiologia Humanas; Higiene; Puericultura e Educação Sanitária; Biologia Geral; Biologia Educacional; Pedagogia; História da Educação; Filosofia da Educação; Psicologia Geral; Psicologia Educacional; Sociologia Geral; Sociologia Educacional; Metodologia do Ensino Primário e 
Prática do Ensino Primário; Literatura Infantil; Desenho Pedagógico; Música e Canto Orfeônico; Artes Aplicadas; Educação Física; Recreação e Jogos; Medidas Educacionais; Instruções Escolares (SÃO PAULO, 1947).

Essas matérias eram distribuídas em cadeiras, assim definidas:

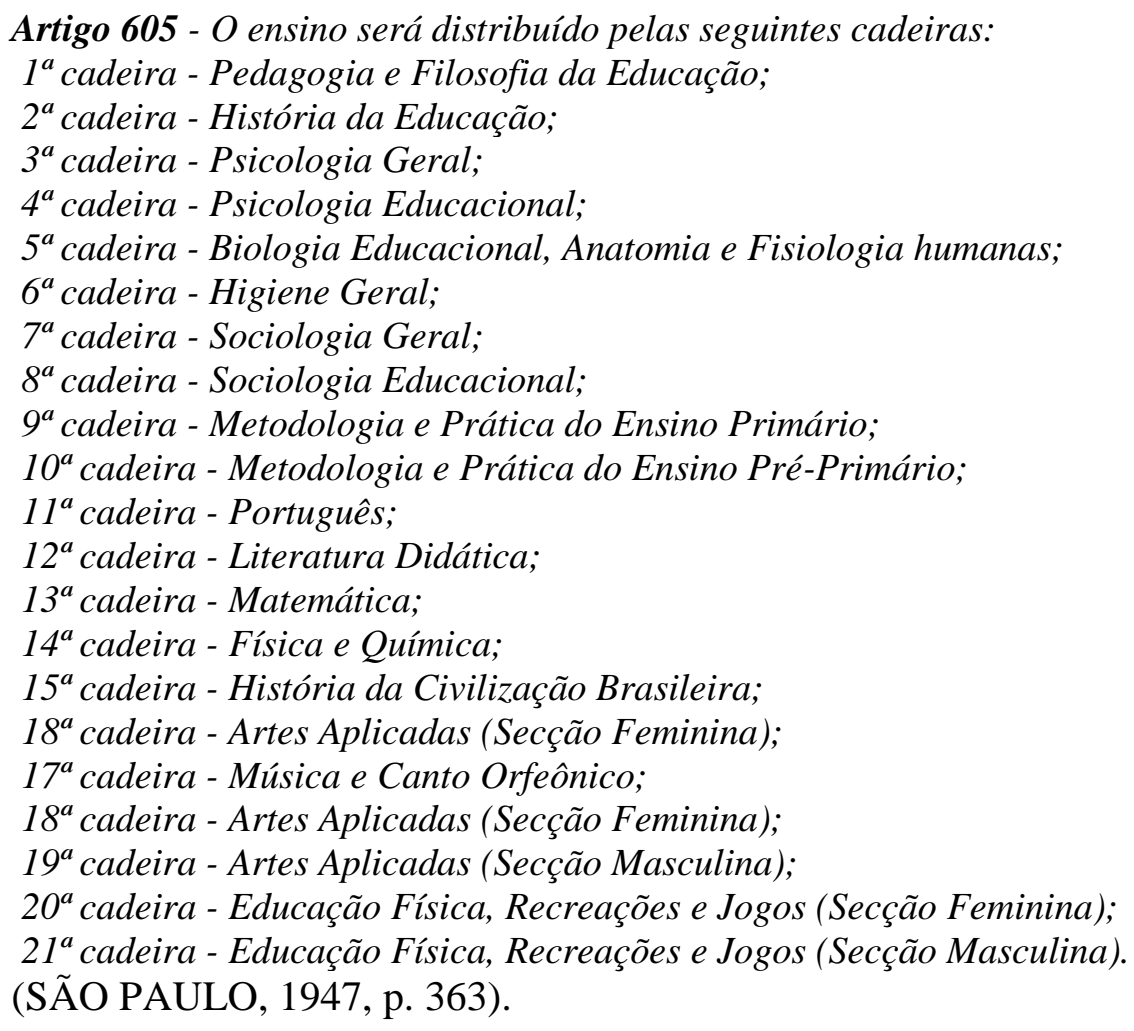

Em relação à matéria "Literatura infantil", ela integrava a $11^{\text {a }}$ cadeira - "Português" -, do Curso Normal do IE "Caetano de Campos", sendo ministrada no $3^{\circ}$. ano desse curso, com carga horária de duas horas-aula semanais.

Devido às reformas estabelecidas nos currículos dos Cursos Normais paulistas pelo Decreto de 1947, era necessária uma readequação dos programas de ensino, que vigoravam até então. No entanto, até o ano de 1954, continuou em vigor o documento Programmas das escolas normaes, publicado em 1938.

Somente no ano de 1954 é que foi publicado novo documento contendo os programas de ensino dos cursos normais, condizentes com a reforma estabelecida pelo Decreto $\mathrm{n}^{\circ}$. 17.698, de 1947. Trata-se do documento Programas das escolas normais $e$ instruções metodológicas, publicado em 2 de dezembro de 1954.

Os programas de ensino publicados em 1954, por referirem-se aos Cursos Normais oferecidos em todas as Escolas Normais do estado de São Paulo, foram elaborados de acordo com a organização do Curso Pré-Normal e Curso de Formação Profissional do Professor. Por essa razão, neles não constam as prescrições relativas às matérias que compunham a formação de professores no IE "Caetano de Campos".

Apesar de não haver programas de ensino específicos para as matérias do currículo do Curso Normal do IE "Caetano de Campos", como era o caso da matéria "literatura infantil", desde que ela foi criada em 1947 e passou a fazer parte da formação dos professorandos nesse curso, passaram a ser publicados manuais de ensino que continham capítulos destinados ao ensino da literatura infantil. 
Nesses capítulos, é possível identificar os conteúdos relativos à matéria "Literatura infantil", como: conceito de literatura infantil; finalidades da literatura infantil; requisitos dos livros infantis; contos populares e folclore; os contos de fadas; literatura infantil brasileira (tradicional e moderna); biblioteca escolar; e poesia (BUDIN, 1949; CARNEIRO, 1955; D’ÁVILA, 1954).

Além disso, esses manuais tiveram ampla circulação entre os normalistas do estado de São Paulo, pois é recorrente a localização de seus exemplares em bibliotecas de antigas escolas normais e Institutos de Educação. Esse aspecto possibilita presumir que o ensino da literatura infantil se dava com base nos conteúdos prescritos e estruturados nesses manuais que continham capítulo destinado ao ensino da literatura infantil.

\section{A Reforma dos Cursos Normais paulistas, em 1957, e a institucionalização da disciplina "Literatura infantil" em todo o estado}

Embora desde 1947 a matéria "Literatura infantil" fizesse parte do currículo do Curso Normal do IE "Caetano de Campos", somente depois de dez anos em que essa matéria foi criada é que ela passou a integrar o currículo ${ }^{3}$ de todos os Cursos Normais do estado de São Paulo.

Essa mudança no currículo dos Cursos Normais paulistas se deveu ao fato de que esses cursos passaram por nova reforma, com a publicação da Lei $n^{\circ}$. 3.739, de 22 de janeiro de 1957.

Dentre as alterações promovidas por essa Lei: foi extinto o curso Pré-Normal, que passou a constituir o primeiro ano do Curso Normal; foi instituído o Curso Normal de três anos no período diurno e de quatro anos no período noturno; e foi estabelecido novo currículo para os Cursos Normais (SÃO PAULO, 1957).

Além dessas alterações, a partir da promulgação dessa Lei, “[...] o currículo, que anteriormente compreendia 'matérias' cujo ensino era distribuído em 'cadeiras' (que abrangiam uma ou mais 'matérias'), passou a ser distribuído em 'disciplinas" (LABEGALINI, 2005, p. 99). Dentre essas disciplinas, literatura infantil constituiu-se como disciplina dos Cursos Normais.

De acordo com a Lei $n^{\circ} .3 .739$, de 1957, as disciplinas dos Cursos Normais do estado de São Paulo ficaram assim definidas:

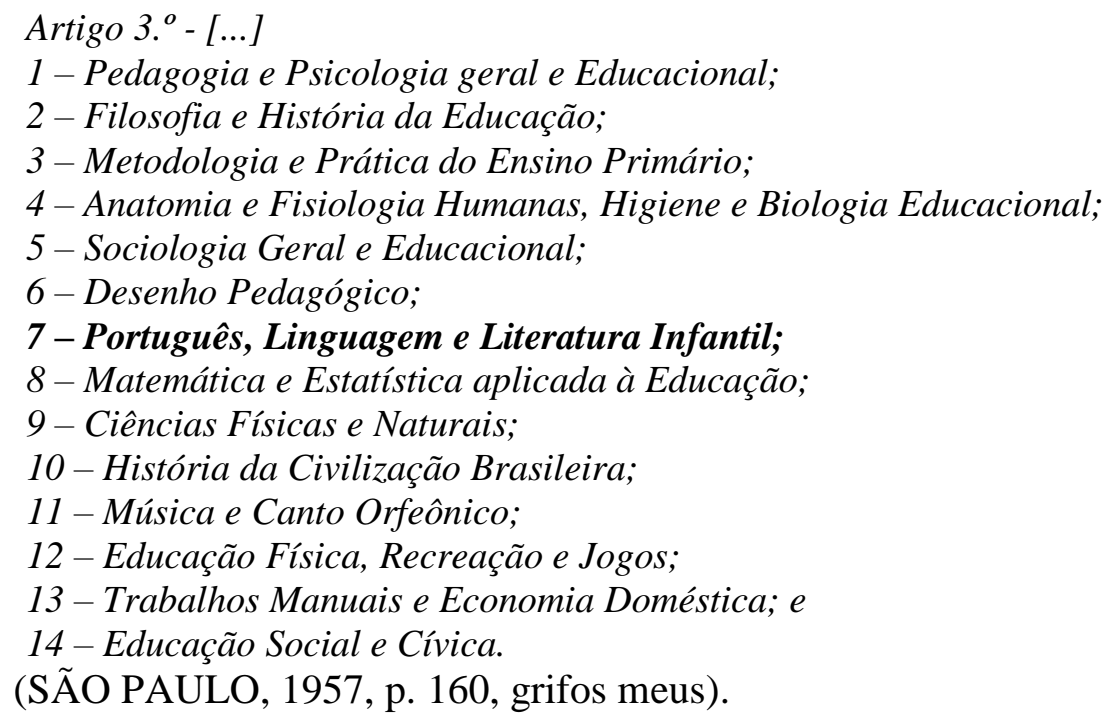


Diferentemente do Decreto de 1947, nessa Lei de 1957 não eram estabelecidos organização e currículo específicos para o IE "Caetano de Campos". E, a partir de 1957, todos os Cursos Normais paulistas passaram a funcionar do mesmo modo.

Especificamente em relação ao caso da disciplina "Literatura infantill", foi a partir dessa uniformização que ela passou a fazer parte da formação de todos os professorandos de Cursos Normais do estado de São Paulo.

Devido a essas alterações, no ano de 1958 foram publicados novos programas de ensino para os Cursos Normais paulistas. Esses programas de ensino foram publicados por meio do Comunicado $\mathrm{n}^{\circ}$. 18, de 3 de março de 1958, que definia que a disciplina "Literatura infantil" devia ser ministrada no $3^{\circ}$. ano do Curso Normal, com carga horária de duas horas-aula semanais.

Ainda de acordo os programas de ensino publicados em 1958, o ensino da literatura infantil foi assim prescrito:

1 - Origem e desenvolvimento da literatura infantil.

a) A tradição oral.

b) Fábulas, viagens, contos de fadas para adultos.

c) Primeiras coletâneas dos Contos Maravilhosos para adultos.

d) A literatura de ficção recreativa no século XIX.

e) A literatura infantil no Brasil. Os precursores (Século XIX), os propulsores do movimento: homens de letras e professôres (século XX).

f) A expansão da literatura infantil brasileira nos últimos tempos. As publicações infanto-juvenis.

2 - Caracterização da literatura.

a) A literatura didática e a recreativa; fases e modalidades.

b) $\mathrm{O}$ ajustamento do literato à evolução da criança: a fase do egocentrismo e da socialização.

c) A poesia na literatura infantil: Os pequenos poemas e as fábulas em verso. Os cantos escolares.

d) Os requisitos literários morais e material do livro de literatura infantil.

3 - Finalidades didática, psicológicas, sociais e morais da literatura infanto-juvenil.

4 - A biblioteca escolar, infanto-juvenil finalidade e organização. Clubes de leitura.

5 - O Teatro Infantil: representações infantis, teatro de sombras, de bonecos, de fantoches.

(SÃO PAULO, 1958, p. 7-8).

Um ano após a publicação desse programa de ensino, foi publicado o Decreto $\mathrm{n}^{\circ}$. 35.100, de 17 de junho de 1959, que revogou a Lei $\mathrm{n}^{\circ} .3 .739$, de 1957, e estabeleceu nova organização para os Cursos Normais do estado de São Paulo. Dentre as mudanças proporcionadas por esse Decreto de 1959, têm-se:

Artigo $3^{\circ}$ - O Curso de Formação destinar-se-á a formar professôres para ensino primário comum.

Artigo $4^{\circ}-O$ Curso de Aperfeiçoamento destinar-se-á ao aperfeiçoamento profissional dos professôres primários. 
Artigo $5^{\circ}$ - Os Cursos de Especialização destinar-se-ão à especialização de professôres primários tanto para a administração escola como para o ensino.

(SÃO PAULO, 1959, p. 156).

Por causa da reforma estabelecida nos Cursos Normais paulistas pelo Decreto $\mathrm{n}^{\circ}$. 35.100 , de 1959, foram publicados nesse mesmo ano novos programas de ensino por meio da Portaria $\mathrm{n}^{\circ}$. 69, de 10 de setembro de 1959. A partir dessa Portaria a disciplina "Literatura infantil" passou a ser organizada da seguinte forma:

II-Literatura infantil:

a) Origem e desenvolvimento;

b) Literatura folclórica;

c) Literatura de ficção no século XIX;

d) Literatura infantil no Brasil: precursores e propulsores do movimento;

e) Teatro Infantil;

f) Poesia na Literatura infantil;

g) Objetivos da literatura infanto-juvenil: Didático, Psicológico, Social e Moral.

h) Biblioteca escolar infanto-juvenil

(SÃO PAULO, 1960, p. 45).

A publicação desses novos programas para os Cursos Normais, relativamente à disciplina "Literatura infantil", não contém grandes mudanças comparativamente aos programas anteriores. $\mathrm{O}$ que se alterou foi a denominação dos conteúdos desse programa de ensino, os quais, no Programa de 1959, são mais sintéticos relativamente ao Programa de 1958.

Esse novo programa, de 1959, permaneceu em vigor até meados da década de 1960, quando novamente os Cursos Normais paulistas foram reorganizados em função da publicação da Lei de Diretrizes e Bases da Educação Nacional (LDB), Lei $\mathrm{n}^{\circ}$. 4.024, de 20 de dezembro de 1961.

A partir dessa LDB, que estabeleceu uma série de mudanças em todos os níveis de ensino brasileiro (SAVIANI, 2009), os cursos de formação de professores passaram a ser organizados em Escola Normal de grau ginasial, que formaria o "regente do ensino primário", e Escola Normal de grau colegial, que formaria o professor primário (ALMEIDA, 1993).

Devido a essas mudanças, para regulamentar os Cursos Normais do estado de São Paulo, foi publicado o Decreto $\mathrm{n}^{\circ}$. 45.159-A, de 19 de agosto de 1965, que estabeleceu novo currículo para os Cursos Normais do estado de São Paulo. O novo currículo estabelecido por esse Decreto não contém a indicação da disciplina "Literatura infantil", no entanto, por meio de documentos que constam em Escolas Normais e Institutos de Educação do estado de São Paulo, essa disciplina continuou integrando o currículo dos Cursos Normais após a publicação do Decreto de 1965.

Após essas mudanças, com o objetivo de melhorar o nível do ensino normal e integrar o ensino Colegial e o Normal, foi promulgado no estado de São Paulo o Decreto $\mathrm{n}^{\circ}$. 50.133, de 2 de agosto de 1968, o qual organizou os Cursos Normais da seguinte forma: as duas primeiras séries desse curso foram unificadas com o ensino colegial; a $3^{\text {a }}$ série passou a ser organizada em áreas de estudos; e $4^{\mathrm{a}}$ séries passou a concentrar as disciplinas profissionalizantes. 
A partir desse Decreto de 1968, a disciplina "Literatura infantil" passou a integrar o conjunto das disciplinas obrigatórias a serem ministradas na $3^{\mathrm{a}}$. ou $4^{\mathrm{a}}$. série dos Cursos Normais paulistas. E os programas de ensino referentes à disciplina "Literatura infantil" permaneceram os mesmos publicados em 1959, por meio da Portaria $\mathrm{n}^{\circ}$. 69, de 10 de setembro de 1959.

Além da publicação desses programas de ensino, entre as décadas de 1950 e 1960, com a obrigatoriedade do ensino da literatura infantil em todos os cursos de formação de professores primários do estado de São Paulo, também passaram a ser publicados manuais pedagógicos destinados especificamente ao ensino da literatura infantil. O primeiro deles foi publicado em 1959 e trata-se do seguinte manual: Compêndio de literatura infantil: para o $3^{\circ}$ ano normal, de autoria de Bárbara Vasconcelos de Carvalho. Além desse, foram publicados, nesse período, os seguintes manuais: Literatura infanto-juvenil: de acôrdo com o programa das escolas normais, de Antonio d'Ávila, publicado em 1961; Pontos de literatura infantil, de José Benedicto Pinto, publicado em 1967; e Como ensinar literatura infantil: para os colégios normais, de Maria Antonieta Antunes Cunha, publicado em 1968.

Esses manuais, como os seus respectivos subtítulos indicam, seguiam, fielmente, as prescrições para o ensino da literatura infantil contidas nos programas de ensino do estado de São Paulo, de modo que os capítulos, por vezes, seguem a mesma denominação dos pontos indicados nesses programas ${ }^{4}$.

\section{A extinção dos Cursos Normais e a criação dos cursos de formação de professores em nível de $2^{\circ}$ grau}

No início da década de 1970, no auge da ditadura militar brasileira, foi promulgada a Lei $\mathrm{n}^{\circ} .5 .692$, de 11 de agosto de 1971 , que fixou as bases para o ensino de $1^{\circ}$. e $2^{\circ}$. graus no Brasil, a partir da qual os Cursos Normais foram extintos; e foram criados os cursos denominados Habilitação Específica de $2^{\circ}$. Grau para o Magistério (HEM).

Além dessa alteração, os Institutos de Educação e Escolas Normais, que antes ofereciam os Cursos Normais, foram transformados em escolas de $2^{\circ}$. Grau, nas quais era oferecida a HEM.

Especificamente no estado de São Paulo, para se adequar à Lei n ${ }^{\circ} .5 .692$, de 1971, foi publicado o Comunicado $\mathrm{n}^{\circ}$. 4, de 31 de janeiro de 1975, contendo "Sugestão de currículo para o curso de formação de professores em nível de $2^{\circ}$. Grau", na qual a disciplina "Literatura infantil" passou a integrar o conjunto de disciplinas da parte diversificada do currículo da HEM, devendo ainda ser ministrada na $3^{\mathrm{a}}$. e $4^{\mathrm{a}}$. séries desse curso.

Também para se adequar à Lei $\mathrm{n}^{\circ}$. 5.692, de 1971, o currículo dos cursos de formação de professores passou a serem organizado em "núcleo comum", "mínimos profissionalizantes" e "parte diversificada" e, além disso, no caso do estado de São Paulo, o Conselho Estadual de Educação, por meio da Deliberação n ${ }^{\circ}$. 21, de 1976, instituiu o curso denominado "Aprofundamento", que ocorria na 4". série da HEM. Esses cursos de "Aprofundamento" podiam se referir às seguintes "áreas": Pré-Escola; $1^{\mathrm{a}}$. e $2^{\mathrm{a}}$. séries; e $3^{\mathrm{a}}$. e $4^{\text {a }}$. séries do $2^{\circ}$. Grau (ALMEIDA, 1993, p. 101).

No caso da disciplina "Literatura infantil", ela integrava o currículo de todos os cursos de "Aprofundamento" da HEM.

Em decorrência da implementação da HEM no estado de São Paulo, a Coordenadoria de Estudos e Normas Pedagógicas do Estado de São Paulo (CENP), órgão 
vinculado à Secretaria de Estado da Educação e responsável pela elaboração de documentos relativos à educação, publicou, no ano de 1981, o documento Habilitação Específica de $2^{\circ}$. Grau para o Magistério: guias curriculares para a parte diversificada da formação especial, no qual se apresentam sugestões relativas às disciplinas "Estatística Aplicada", "Técnicas de Avaliação do rendimento escolar" e "Literatura infantil".

Especificamente em relação à disciplina "Literatura infantil", nesse documento constam "[...] sugestões para a elaboração de um planejamento de curso que [...] serão úteis para o desenvolvimento desse componente curricular." (SÃO PAULO, 1981, p. 9).

A elaboração das "sugestões" para a disciplina "Literatura infantil" foi elaborada por Zélia de Almeida Cardoso ${ }^{5}$, com a seguinte estrutura: introdução e justificativa para o ensino da literatura infantil; os objetivos da disciplina; os conteúdos programáticos; procedimentos; sugestões para elaboração de um plano de ensino; sugestões para elaboração de um cronograma; sugestões para o planejamento de pesquisa; sugestões para escolha de textos teóricos para cada "tema" dos conteúdos programáticos; sugestões de coleções de livros de literatura infantil; e sugestão de bibliografia teórica sobre literatura infantil.

De acordo com o documento Habilitação Específica de $2^{\circ}$. Grau para o Magistério: guias curriculares para a parte diversificada da formação especial, a justificativa para a disciplina "Literatura infantil" fazer parte da HEM decorre do fato de que os professores, "[...] que terão a seu cargo a educação de crianças, se reveste da maior importância se atentarmos para o fato de que essa disciplina colocar o professorando em face da problemática que envolve a leitura feita pela criança." (SÃO PAULO, 1981, p. 31).

Para tanto, nesse documento, os conteúdos programáticos da disciplina "Literatura infantil" estão divididos em quatro unidades, assim organizadas: unidade I, conceito de literatura infantil, função da literatura infantil, gêneros literários e infância; unidade II, acesso ao texto literário na antiguidade, literatura infantil nos séculos XVI, XVII e XVIII, literatura infantil no século XIX, literatura infantil no século XX; unidade III, origem da literatura infantil no Brasil, os "pioneiros" da literatura infantil; Monteiro Lobato; autores especializados; literatura infantil na atualidade; e unidade IV, características da criança brasileira; o livro infantil no Brasil e bibliotecas escolares e infantis (SÃO PAULO, 1981).

Concomitantemente ao funcionamento da HEM, a partir do final da década de 1980, passaram a ser criados, por iniciativa do Ministério da Educação, os Centros de Formação e Aperfeiçoamento do Magistério (CEFAM), nos quais era oferecido curso de formação de professores. O projeto do CEFAM foi lançado pelo Ministério da Educação como forma de revitalizar a formação de professores, frente ao quadro de precariedade e de problemas que apresentava a HEM (SAVIANI, 2009).

No caso do estado de São Paulo, os CEFAMs passaram a ser instalados no ano de 1987 e a legislação que regulamentava a organização do currículo dos cursos de formação de professores neles ministrados era a mesma da HEM, ou seja, no caso da disciplina "Literatura infantil", nos cursos oferecidos nos CEFAMs, o que vigorou em relação ao ensino da literatura infantil foram as prescrições contidas no documento Habilitação Específica de $2^{\circ}$. Grau para o Magistério: guias curriculares para a parte diversificada da formação especial.

Somente ao longo da década de 1990, com o gradativo fechamendo da HEM no estado de São Paulo, a Secretaria de Estado da Educação passou a publicar legislação específica para os cursos ministrados nos CEFAMs. No entanto, no caso específico das disciplinas da parte diversificada do currículo, como era o caso da disciplina "Literatura infantil”, permaneceu em vigência o documento publicado pela CENP, em 1981. 
Além disso, no caso dos CEFAMs do estado de São Paulo, "Literatura infantil" constava como disciplina optativa da parte diversificada do currículo, podendo fazer parte, ou como disciplina curricular ou como conteúdo programático da disciplina "Conteúdos metodológicos de língua portuguesa", conforme escolha de cada CEFAM.

Desse modo, "Literatura infantil" permaneceu no currículo dos cursos de formação de professores até o ano de 2003, quando foi publicada a Resolução $\mathrm{n}^{\circ}$. 119, a qual foi responsável pela extinção, nesse estado, dos CEFAMs e das HEM remanescentes. Esses cursos foram extintos no estado de São Paulo e em todos os estados brasileiros em decorrência da LDB, Lei $\mathrm{n}^{\circ}$. 9.394, de 20 de dezembro de 1996, que fixou a obrigatoriedade da formação dos professores das séries iniciais do Ensino Fundamental em cursos de nível superior.

\section{A disciplina "Literatura infantil" e a conformação de práticas de ensino desse gênero literário (Considerações finais)}

Pelo exposto aqui, a análise dos resultados obtidos possibilita compreender que ao longo dos quase 60 anos de história da disciplina "Literatura infantil" nos cursos de formação de professores primários no estado de São Paulo, embora se observe diferentes reformas e reestruturações dos currículos desses cursos, o ensino da literatura infantil não sofreu grandes alterações no que se refere ao conjunto de saberes relativos à sua correspondente disciplina.

Como se observa também pelas informações apresentadas, as constantes reformas dos cursos de formação de professores e as reorganizações curriculares, no caso da disciplina "Literatura infantill", pouco alteraram os conteúdos dessa matéria/disciplina, de modo que, questões como conceito de literatura infantil, suas funções, sua história, suas diferentes modalidades (poesia, teatro e narrativa), sua relação com o folclore e a organização de bibliotecas foram assuntos recorrentes desde a sua criação, em 1947, até a sua extinção, em 2003.

Também é possível observar que o modo como o ensino da literatura infantil esteve organizado remete à ideia de que a disciplinarização desse gênero literário esteve fortemente ligada a projetos de Educação/Nação, no qual essa arte literária estava à serviço de fins educativos de maior amplitude, como a formação de leitores, a transmissão (do ponto de vista psicológico) de valores socialmente aceitos e o ensino "agradável" de outros conteúdos escolarizadas.

Além disso, apesar do pouco espaço que essa disciplina tinha na formação de professores, a sua permanência por um período relativamente extenso e quase sem alterações no currículo dos Cursos Normais, HEM e CEFAMs foi decisiva e fundamental para a conformação de práticas de ensino e de uso da literatura infantil nas escolas, praticas essas que ainda se observa em vigência, no Brasil.

Ainda hoje a discussão sobre as "funções" do livro infantil, suas contribuições para a formação "psicológica" da criança, a importância de se adequar os livros às "idades cronológicas" figuram no imaginário e na prática dos professores das séries iniciais. E, apesar de o campo da pesquisa sobre literatura infantil vir indicando outros modos de se pensar e compreender esse ensino, o que parece permanecer são as práticas de ensino que se assemelham às praticas de ensino disseminadas por meio da disciplinarização da literatura infantil na formação de professores ao longo do século XX. 
Por fim, a história da disciplina "literatura infantil" possibilita, ainda, compreender aspectos mais específicos da formação de professores e da História da Educação brasileira, como a problematização sobre em que medida o modelo de formação de professores se alterou, ou não, com os processos de reforma e de implementação de políticas educativas ao longo do século XX brasileiro.

\section{Referências bibliográficas}

ALMEIDA, Jane Soares de. A escola normal paulista: estudo dos currículos (1846 a 1990) destaque para a prática de ensino. Boletim do Departamento de didática, Araraquara, a. 11, n.9, p. 1-157, 1993.

ARROYO, Leonardo. Literatura infantil brasileira: ensaio de preliminares para a sua história e suas fontes. São Paulo: Melhoramentos, 1968.

BERTOLETTI, Estela Natalina Mantovani. A produção de Lourenço Filho sobre e de literatura infantil e juvenil (1942-1968): fundação de uma tradição. 2006. 275f. Tese (Doutorado em Educação) - Faculdade de Filosofia e Ciências, Universidade Estadual Paulista, Marília. 2006.

BUDIN, J. Metodologia da linguagem: para uso das escolas normais e institutos de educação. São Paulo: Companhia Editora Nacional, 1949.

CARNEIRO, Orlando Leal. Metodologia da linguagem. Rio de Janeiro: Agir, 1951.

D’ÁVILA, Antônio. Práticas escolares: de acordo com o programa de prática do ensino do curso normal e com orientação do ensino primário. v. 3. São Paulo: Saraiva, 1954. p. 210-233.

LABEGALINI, Andréia. C. F. Baraldi. A formação de professores alfabetizadores nos Institutos de Educação do Estado de São Paulo (1933 a 1975). 2005. 315f. Tese (Doutorado em Educação) - Faculdade de Filosofia e Ciências, Universidade Estadual Paulista, Marília, 2005.

MORTATTI, Maria do rosário Longo. Ensino de língua e literatura no Brasil: repertório documental republicano. Marília, 2003. (digitado).

. Bibliografia brasileira sobre história do ensino de língua e literatura no Brasil (2003-2011). Marília, 2011. (digitado).

Autor (2012)

Autor (2013)

SÃO PAULO (Estado). Coleção de Leis e Decretos do Estado de São Paulo. São Paulo: Imprensa Oficial, 1947.

SÃO PAULO (Estado). Coleção de Leis e Decretos do Estado de São Paulo. São Paulo: Imprensa Oficial, 1957.

SÃO PAULO (Estado). Programas do curso normal. São Paulo: Editora do Brasil, 1958. 
SÃO PAULO (Estado). Coleção de Leis e Decretos do Estado de São Paulo 1959. São Paulo: Imprensa Oficial, 1959.

SÃO PAULO (Estado). Legislação do ensino normal no estado de São Paulo. São Paulo: Imprensa Oficial, 1960.

SÃO PAULO (Estado). Habilitação específica de $2^{\circ}$. Grau para o magistério: guias curriculares para a parte diversificada da formação especial. São Paulo: CENP, 1981.

SAVIANI, Dermeval. Formação de professores: aspectos históricos e teóricos do problema no contexto brasileiro. Revista Brasileira de Educação. v.14, n. 40, p. 143-155, jan./abr. 2009.

TANURI, Leonor Maria. História da formação de professores. Revista Brasileira de Educação. São Paulo, n. 14, p. 61-88, mai./ago. 2000. Disponível em: <http://www.anped.org.br/rbe/rbedigital/RBDE14/RBDE14_06_LEONOR_MARIA_TAN URI.pdf > Acesso em: 15/06/2008>

\footnotetext{
${ }^{1}$ Sobre a produção acadêmico-científica brasileira sobre literatura infantil, ver: Mortatti $(2003 ; 2011)$ e Autor (2012).

${ }^{2}$ Este texto decorre de pesquisa de doutorado em andamento, desenvolvida junto ao Programa de PósGraduação em Educação e vinculada a Grupo de Pesquisa.

${ }^{3}$ Utilizo o termo "currículo" para me referir à organização das disciplinas que compunham os cursos de formação de professores a partir de 1957, porque esse é o termo que aparece na legislação paulista desse período.

${ }^{4}$ Para informações mais detalhadas sobre os manuais de ensino de literatura infantil ver, especialmente: Autor (2013).

5 Zélia de Almeida Cardoso nasceu em julho de 1934, graduou-se em Letras Clássicas em 1957, pela Universidade de São Paulo (USP), doutorou-se também em Letras Clássicas em 1976 e obteve o título de Livre-docente em Literatura Latina em 1984. Desde 1976, atua como professora do curso de Letras da USP, na área de literatura latina.
}

Recebido: fev-14 Aprovado: jul-14 